\title{
Introducing TASK
}

\section{Editors' preface to the first edition of TASK}

\author{
Kris Van den Branden and Koen Van Gorp \\ KU Leuven, Belgium $\mid$ Michigan State University, USA
}

We are very proud to present the very first issue of Task. Journal on task-based language teaching and learning. It is an international refereed journal dedicated to promoting and disseminating scholarship and research in the field of Task-Based Language Teaching (TBLT) and learning. In this preface, we will briefly describe the history that led to this journal, define what we mean by task-based language teaching and learning, and describe the main ambitions we as editors have with this journal. We will also reflect on the different types of articles the journal will welcome, and present the articles in this inaugural issue.

\section{The birth of a journal}

In 2005, the first International Conference on Task-based Language Teaching was organized at the University of Leuven (Belgium). The organization of that conference was supervised by the International Association for Task-based Language Teaching, which had been founded by Martin Bygate, John Norris and Kris Van den Branden to support the exchange between scholars interested in this particular approach to language teaching. At the time, the conference and the newly founded association came as a direct response to the growing interest in TBLT among researchers, educational practitioners and policy makers on a worldwide scale.

Building on the guiding principles of Communicative Language Teaching, the rationale behind TBLT had been laid out around two decades earlier, in a number of articles and volumes published in the 1980 os (e.g., Candlin, 1987; Long, 1985; Prabhu, 1987). Most of those publications grew out of a discontent with the way foreign and second language teaching were organized. For instance, Long (1985) claimed that much of what was going on in second language classrooms was based on structure-based approaches like Presentation Practice Production (PPP) and was inconsistent with the way people learn a language. People, so Long argued, 
do not learn to use a language in authentic situations by first acquiring explicit knowledge on discrete units and automatizing their use in isolated, form-focused exercises in a piecemeal and decontextualized fashion. Instead, they need plenty of opportunities to be exposed to authentic, rich, and contextualised input and to produce meaningful output in interaction with the teacher and other learners. In other words, what students do with the target language in the classroom needed to resemble the way people use language in real life more closely.

"Task" served as a key concept to make that clear: in most cases in which people use language in real life, they try to comprehend and produce meaningful messages in order to reach a particular goal. For example, they read a newspaper article to find out more about the COVID 19 restrictions their governments have introduced, they call, email or text a friend to arrange their next meeting, they read a recipe to cook a certain dish, or they tell an anecdote to enjoy their time with their partner. This is reflected in the definition of task offered by Bygate et al. (2001, p.11): "A task is an activity which requires learners to use language, with emphasis on meaning, to attain an objective."

As can be inferred from the examples above, the objectives that task performance serves need not be linguistic in their own right. For instance, they may be related to gaining knowledge, playing games, carrying out instructions, or deciding whether to put on a coat or not after listening to a weather forecast.

Task-based language teaching (TBLT), then, is a research-based approach to language teaching that takes "task", defined as above, as its basic unit of analysis for (a) the description of curriculum objectives; (b) the design and organization of classroom activity; and (c) the assessment and evaluation of students' language development and performance. With regard to (a), the formulation of curriculum objectives aims to reflect the repertoire of tasks that students are expected, or required, to perform in relevant domains and situations outside the language classroom. In many cases, a needs analysis that documents the target tasks that student populations need to be able to perform, is believed to be highly informative in terms of determining key goals (Long, 2015). With regard to (b), classroom activity is built around the performance of tasks, with students getting ample opportunity to use the target language for goal-oriented meaning-making. In a similar vein, the assessment of students' language competences and growth (c) is primarily based on the assessment of the extent to which students are able to perform relevant tasks to criterion, or have become better at doing so.

Since the 1980s, TBLT has steadily gained momentum in the field of foreign/ second language teaching. It is now being advocated by a number of governments around the world as the most favoured approach to language teaching. Meanwhile, the research base on the impact of the use of tasks and task-based approaches on students' use and acquisition of additional languages has kept on 
growing (e.g., Ellis et al., 2020; Long, 2015). In addition, a growing number of publications document the actual use of tasks, and the implementation of TBLT, by teachers in authentic education contexts (e.g., Adams \& Newton, 2009; East, 2012; Samuda et al., 2018).

To encourage the worldwide exchange of research and practice-based insights among researchers, teachers, teacher educators, and policy makers, the Leuven 2005 conference was followed by 7 further conferences: The International Conference on Task-based Language Teaching has turned into a biennial event hosted by universities around the world. In the meantime, the International Association for Task-based Language Teaching became a full-blown non-profit organization (IATBLT vzw.) in 2015. It aims to (a) promote research, applications, and development of TBLT, (b) help to disseminate results and resources, and (c) promote international and interdisciplinary cooperation in the field. At its most recent conference in Ottawa, the Executive Board and General Assembly of IATBLT vzw. made clear that they would wholeheartedly support the founding of a journal fully devoted to TBLT. As the editors of the journal, we are very glad and thankful that many members of the Executive Board and Assembly were found willing to serve on our editorial board and review manuscripts that are submitted to the journal. Beyond any doubt, this will raise the quality of the reviewing process and the manuscripts we will publish. Evidently, we also want to extend our gratitude to John Benjamins Publishing Company for putting so much trust in us, and adding this new journal to their catalogue.

\section{Aims of the journal}

Like many other editors starting up a new journal, our ambitions are high. Below are three of our main aims that we would like to highlight at this point:

1. Support the development of TBLT as a researched pedagogy;

2. Bridge the gap between theory and praxis;

3. Further the theory-building on task-based language teaching and learning.

With regard to the first aim mentioned above, we consider it crucial to emphasize that TBLT is not an ideology or a dogma, but from the very beginning has aimed to be an approach to (second/foreign) language teaching that is fully grounded in empirical research. However, the fact that TBLT has gained popularity and esteem in many countries around the world, and among a growing number of teachers, does not mean that practitioners' requests to show the empirical support for the effectiveness of TBLT have been addressed to a satisfactory degree. In fact, the need for more empirical support underpinning the basic principles behind TBLT 
is still one of the most pressing concerns of practitioners and teacher educators alike. With this journal, we aim to encourage researchers to devote their research work to different aspects of task-based language teaching and learning in diverse pedagogical contexts, and disseminate their work, so that it can strengthen the empirical base and inspire other researchers. In this respect, it is widely known that most of the available research on tasks has involved highly educated university students learning English as an additional language. There is a clear need for more research that involves language learners of different ages and socioeconomic and cultural backgrounds, and with different needs profiles. As editors, we will actively pursue our ambition to extend the range of studies that are published in the TBLT domain.

Likewise, there is a need for more research that is carried out in authentic classrooms. Many of the available studies were carried out in tightly controlled laboratory settings. It remains unclear how relevant the results of those studies really are for teachers, many of whom have to work under strenuous conditions, as a result of (amongst others) large classroom sizes, demanding curricula, highstakes examination systems, heterogeneous student profiles, low salaries, and insufficient infrastructural support. We will therefore encourage researchers to submit manuscripts based on research into the practice of TBLT, especially the use of TBLT in real language classrooms as part of regular pedagogical practices and curricula, and the ways in which TBLT is perceived by teachers and students of a wide range of different backgrounds.

Secondly, we aim to bridge the gap between theory and praxis. The available research on the implementation of TBLT shows that teachers may have strong reservations about TBLT, and even if they don't, may find many obstacles on their way to task-based classroom practice. So far, teachers have also been barely involved in the theory-building; TBLT has largely "come from above": it was designed by applied linguists and teacher educators, and picked up by syllabus developers, commercial publishers, governments, and international organisations. It should come as no surprise, then, that there are often big gaps between "tasks-as-a-workplan" and tasks as they are implemented in the classroom. Since TBLT is an approach to teaching, this journal aims to take teachers' perspective (those who do the actual teaching) seriously. Therefore, we encourage teachers to present their views on and experiences with TBLT as practitioners and researchers.

In that way, we hope that the journal will not only play a role in strengthening the research base underpinning TBLT, but also feed the process of theorybuilding. If TBLT is, indeed, a research-based pedagogy, then its principles and guidelines are provisional, and are open for revision or reconsideration on the basis of the available research. It should be noted, in this respect, that our journal 
will devote specific attention to instances of task-based language learning and teaching that reach well beyond the regular language classroom. Themes such as content-and-language-integrated learning, language across the curriculum, interdisciplinary projects, project-based learning, and the link between language skills and the development of 21st-century competences will be explored from a TBLT perspective. Likewise, the many ways in which second language learners can learn languages outside school in a task-based way will be explored in our journal. This is why the name of our journal not only includes "teaching" but also taskbased learning. We have deliberately added this term to the journal's name, not only because we hope the research published in our journal will document the effects of TBLT on language learning, but also because we want to fully explore the opportunities that language learners are offered today to learn additional languages while performing tasks in all possible environments. For one, through the use of modern technology, the opportunities to learn second and foreign languages outside school have exploded. We hope this journal will turn out to be a rich source of inspiration for many on how to build bridges between different learning environments.

\section{Types of articles}

In an effort to pursue our aims, we will publish different types of articles.

- Original research articles: In each issue of TASK, we will publish peerreviewed articles reporting on empirical studies. We hope to publish studies drawing on a wide diversity of methodologies, both quantitative and qualitative, and involving a wide range of different educational contexts.

- Critical position papers: In this type of paper, an expert in a particular subdomain of task-based language teaching or learning will offer a critical review of the available theory and research, and present their own reflections and recommendations.

- Let's talk tasks: In every issue of TASK, a task, ready for use in an education environment, will be described. A researcher and teacher will critically reflect on its potential. This section will be supervised by Laura Gurzynski-Weiss (Indiana University). Tasks will be selected from the recently launched TBLT Language Learning Task Bank, which is supported by the IATBLT vzw., and which contains a collection of tasks for teachers and researchers. We are very grateful to Laura, the co-creator and project director of the Task Bank, for taking on this exciting task. 
- Current issues in TBLT: In this section of TASK, we will publish interviews, commentaries and classroom explorations. This section aims to provide reflection, discussion or presentation of key topics and evolutions in TBLT theory and practice. It offers a forum for teachers and researchers to share personal perspectives on their own TBLT trajectories and aims to provide valuable information to scholars and practitioners to guide their research and teaching practices.

\section{Introduction to this issue}

This issue contains two critical position papers, two original research articles, an interview with a renowned expert on TBLT, and a discussion of one task from the TBLT Language Learning Task Bank.

The first critical position is an invited paper on task-based curriculum design written by Rod Ellis. His starting point is that TBLT is not monolithic and that different versions exist. As a result, different options are open when it comes to curriculum design from a task-based perspective. To explore possible options, Ellis insists that those interested in designing a task-based curriculum should draw on curriculum theory in general education sciences. Doing so, he distinguishes between three types of curriculum design: (1) a product-oriented model, in which an instructional programme is based on behavioural objectives that specify the changes to take place in students; (2) a process model, that is less prescriptive than the previous model, in that it presents no detailed a priori specification of objectives. Instead, the process curriculum emerges through practice, by giving teachers great autonomy in determining which goals best fit their students' needs and capabilities, while also being appropriate for a particular educational context; (3) Critical Pedagogy, which focuses on the empowerment of students, in the sense that they gain knowledge about power relationships in society and learn to act upon that knowledge; as a result, the $\mathrm{CP}$ curriculum will be the result of negotiation between teachers and students.

Drawing on those models, Ellis then proceeds to critically reflect on four different approaches to TBLT curriculum design: (1) Prabhu's Communicative Language Teaching Project; (2) Long's task-based curriculum model; (3) Willis's framework for task-based language learning; and (4) Ellis's modular curriculum. None of the four models, so Ellis argues, links the language curriculum to a broader education curriculum or pays sufficient heed to the students' overall moral and intellectual development. In the final part of the paper, Ellis therefore makes a number of suggestions. While advocating a broader view on TBLT, which addresses the students' overall intellectual, moral, and social development, he also 
emphasizes the importance of environmental factors in determining what version of a TBLT curriculum is best suited to a particular instructional context. He is also strongly in favour of involving teachers in the development of all stages of curriculum development, and placing greater store on local practitioner research.

The second critical position is an invited paper on the relationship between Instructed Second Language Acquisition (ISLA) and TBLT written by Shawn Loewen and Masatoshi Sato. The authors state that ISLA and TBLT share many concerns and have similar goals, however, whereas TBLT is a pedagogic and curricular approach within ISLA, ISLA itself is a research domain open to investigating the impact and effects of a variety of theories, approaches and methods in second or foreign language learning and teaching. After providing a brief overview of TBLT and ISLA, Loewen and Sato explore the similarities and differences between the two areas of inquiry. Both TBLT and ISLA examine how to create an effective and efficient language learning environment by manipulating learning conditions and mechanisms in a systematic manner. They try to explain how L2 learners' language develops and draw partly on the same theories, i.e., cognitive-interactionist and sociocultural theories, to do so. However, since ISLA is interested in both implicit and explicit learning or instruction, whereas TBLT is mainly interested in the first, ISLA looks at other theories, for example skill acquisition, as well. The idea that ISLA adopts a somewhat broader view is reiterated throughout the similarities and differences sections. For example, the authors argue that TBLT may have focused too much on CALF (complexity, accuracy, lexical complexity and fluency) measures as task performance measures rather than looking more widely at L2 development measures. Alternatively, TBLT pays more attention to specific constructs like implicit learning, needs analysis and assessment that are key to TBLT, but that are not as central to other approaches and methodologies in ISLA. Looking ahead, Loewen and Sato identify two common challenges for TBLT and ISLA: (1) addressing the research-pedagogy link and creating a continued collaboration between researchers and teachers, and (2) investigating how technology can facilitate language learning, and especially the development of implicit knowledge. Finally, Loewen and Sato discuss the issues TBLT raises for ISLA (curricular thinking; the role of a needs analysis and assessment) and issues that ISLA raises for TBLT (TBLT's relationship to TaskSupported Language Teaching; a clear focus on L2 acquisition; consistent use of terms). The authors hope that examination of the close relationship between TBLT and ISLA will help researchers take stock and help advancing both areas of inquiry into the future.

In their original research article, Frijns and Van den Branden present a study into the early acquisition of Dutch as a second language by young children in a Flemish pre-primary school. The study was part of Frijns' Ph.D research, and 
adopted an innovative design: one group of children was actively engaged in a problem-solving task based on an oral narrative, while another was allowed to overhear the interactions between group one and their teacher while being asked to perform another, non-linguistic task in the meantime (i.e., colour a drawing). Children's acquisition of L2 vocabulary that was embedded in the problem-solving task was measured through a pretest - posttest design. In addition, pictures of the children's parents were hung up against the walls, to test whether the affective priming believed to be caused by the pictures had any positive impact on the children's L2 vocabulary acquisition. As the results of the study showed, the latter turned out not to be the case. Active participation in the task-based problem-solving interactions, and overhearing those conversations, did have a significantly positive impact on target language vocabulary acquisition. The authors find the results encouraging, because the setting in which some kids directly interacted with the teacher and others could not - because they were busy in another corner but could still overhear the (interesting) conversation - actually reflects current practice in many pre-primary classrooms in Flanders today. That the children who were given the opportunity to actively participate in the task-based interaction made the greatest gains, is in line with other research on the early language acquisition by young children which emphasizes the power of high-quality conversation and task-based language learning.

In the second original research article, Duong et al. explore the differential effects of spoken input-based and output-based tasks on vocabulary knowledge gains measured at different levels of sensitivity (i.e., spontaneous use, form recall, meaning recall) in 64 Vietnamese EFL university students. The study employed a pretest - posttest design with two experimental groups who completed both input- and output-based tasks in a counterbalanced way (hence the two experimental conditions) and a comparison group who was exposed to L2 input-only (i.e., watching L2 captioned videos about tourist attractions). In the input tasks, students pretending to be tour operators read emails or watched L2 captioned videos. In the output tasks, students described their travel experiences and presented a travel itinerary to foreign tourists visiting Vietnam. This study advances our knowledge of tasks as there are few task-based studies that explore and compare the effects of an input-only condition with an input- and output-based task condition on L2 vocabulary learning in a counter-balanced design. The findings showed that participants who were only exposed to L2 input showed modest learning gains. They learned on average 1 to 2 words in the three tests (i.e., spontaneous use, form recall and meaning recall). However, the participants who completed the input-based and output-based tasks learned significantly more words than participants in the input-only condition in two of the three vocabulary tests. On average, they learned 5 out of 16 words at the form recall level and 6 out of 
13 words at the meaning recall level. The authors conclude that input-based tasks can lead to significantly more learning gains than providing input-only (without a task), and emphasize the value of combining input and output activities for vocabulary learning.

In addition to the two position papers and two research studies, this inaugural issue also contains an interview with Martin Bygate. Martin Bygate is currently an honorary professor at the Department of Linguistics and English Language of Lancaster University. He was one of the founding members of the International Association for Task-Based Language Teaching. In 2019, he was granted the Distinguished Achievement Award at the 8th International Conference on Task-Based Language Teaching. In the interview Bygate reflects on his longstanding career as a teacher and researcher, and engages in some "blue-sky thinking" about TBLT. He talks about how his interest in TBLT came about, the progress TBLT as a field has made, and what he considers to be the most important future challenges for TBLT. One of those challenges is how tasks can provide an interface to the language curriculum and how they can ensure coverage of the whole language curriculum. In line with Ellis', and Loewen and Sato's position papers, Bygate advocates for teachers to be more closely involved in TBLT research and for granting more resources to both teachers and researchers to advance TBLT as a researched pedagogy.

Finally, as editor of the Let's talk tasks section and Director of the TBLT Language Learning Task Bank (tblt.indiana.edu), Laura Gurzynski-Weiss (Indiana University) presents one task from the newly launched Task Bank. She chose a decision-making and writing task in which students in an advanced undergraduate-level Business Spanish course need to collaborate to recommend the hiring of an individual for a cellphone company in Spain, and need to write a letter to the Chief Executive Officer (CEO) of the company justifying their recommendation. As we aim to build up a rich and diversified view of what tasks are like and how they can be used in different contexts, this section also provides reflections on the task from different stakeholders holding multiple perspectives.

To conclude, as editors, we hope that this varied inaugural issue sets the tone for the future issues of TASK, and that it will inspire researchers, teacher trainers and teachers to explore the potential of task-based language learning and teaching in their own contexts.

\section{References}

Adams, R., \& Newton, J. (2009). TBLT in Asia: Opportunities and constraints. Asian Journal of English Language Teaching, 19, 1-17. http://www.airitilibrary.com/Publication /alDetailedMesh?DocID=P20180321001-200912-201803220005-201803220005-1-17 
Bygate, M., Skehan, P., \& Swain, M. (Eds.). (2001). Researching pedagogic tasks: Second language learning, teaching, and testing. Longman.

Candlin, C. (1987). Towards task-based language learning. In C. Candlin \& D. Murphy (Eds.), Language learning tasks (pp. 5-22). Prentice Hall International.

East, M. (2012). Task-based language teaching from the teachers' perspective. John Benjamins. https://doi.org/10.1075/tblt.3

Ellis, R., Skehan, P., Li, S., Shintani, N., \& Lambert, C. (2020). Task-based language teaching. Theory and Practice. Cambridge University Press.

Long, M. (1985). A role for instruction in second language acquisition: Task-based language teaching. In K. Hylstenstam \& M. Pienemann (Eds.), Modelling and assessing second language acquisition (pp. 77-99). Multilingual Matters.

Long, M. (2015). Second language acquisition and task-based language teaching. WileyBlackwell.

Gurzynski-Weiss, L., \& IATBLT (n.d.). The TBLT Language Learning Task Bank. https://tblt .indiana.edu

Prabhu, N. (1987). Second language pedagogy. Oxford University Press.

Samuda, V., Van den Branden, K., \& Bygate, M. (Eds.). (2018). Task-Based Language Teaching as a Researched Pedagogy. John Benjamins. https://doi.org/10.1075/tblt.12

\section{Address for correspondence}

Kris Van den Branden

KU Leuven

Blijde Inkomststraat 7

3000 Leuven

Belgium

kris.vandenbranden@kuleuven.be

https://orcid.org/oooo-ooo1-8348-7034

\section{Co-author information}

\section{Koen Van Gorp}

Second Language Studies

Michigan State University

vangorpk@msu.edu

(iD) https://orcid.org/oooo-0oo2-2033-3852 